OPEN ACCESS

Edited by:

Shakeel Ahmad, Bahauddin Zakariya

University, Pakistan

Reviewed by:

Rouhollah Amini,

University of Tabriz, Iran

Alireza Pirzad,

Urmia University, Iran

*Correspondence:

Khalid Oufdou

oufdou@uca.ma

Specialty section:

This article was submitted to

Plant-Soil Interactions,

a section of the journal

Frontiers in Agronomy

Received: 01 July 2021

Accepted: 04 October 2021

Published: 01 November 2021

Citation:

Raklami A, Bechtaoui N, Tahiri A, Slimani A, Bargaz A, Meddich A and Oufdou K (2021) Co-inoculation With Rhizobacteria and Mycorrhizae Can Improve Wheat/Faba Bean Intercrop Performance Under Field Conditions.

Front. Agron. 3:734923.

doi: 10.3389/fagro.2021.734923

\section{Co-inoculation With Rhizobacteria and Mycorrhizae Can Improve Wheat/Faba Bean Intercrop Performance Under Field Conditions}

\author{
Anas Raklami ${ }^{1,2}$, Noura Bechtaoui ${ }^{1,3}$, Abdel-ilah Tahiri ${ }^{1,2}$, Aiman Slimani ${ }^{1,2}$, \\ Adnane Bargaz ${ }^{3}$, Abdelilah Meddich ${ }^{2}$ and Khalid Oufdou ${ }^{1,3 *}$
}

${ }^{1}$ Laboratory of Microbial Biotechnologies, Agrosciences, and Environment (BioMAgE), Faculty of Sciences Semlalia, Cadi Ayyad University, Marrakech, Morocco, ${ }^{2}$ Laboratory of Agro-Food, Biotechnologies, and Valorization of Plant Bioresources (Agrobioval), Faculty of Sciences Semlalia, Cadi Ayyad University, Marrakech, Morocco, ${ }^{3}$ Agrobiosciences, Plant-Microbe Interactions Laboratory, Mohammed VI Polytechnic University (UM6P), Benguerir, Morocco

Current challenges of climate changes and demographic expansion have imposed increasing awareness about innovation in sustainable agricultural practices. Farming practices like intercropping have many benefits in terms of nutrient use and yield stability. Improving the performance of intercropping systems by the application of beneficial microorganisms (rhizobacteria and/or mycorrhizae) constitutes a promising strategy. In this regard, this study aimed to assess the effect of inoculation with beneficial microorganisms on wheat as monocrop or intercrop with faba bean, using four inoculation treatments: (i) inoculation with rhizobacteria, (ii) inoculation with mycorrhizae, (iii) inoculation with the rhizobacteria-mycorrhizae consortium, and (iv) a control treatment consisting of uninoculated plants. Results showed that rhizobacteria-mycorrhizae co-inoculation under intercropping system improved plant dry weight and spike weight of wheat by 375 and $162 \%$, respectively, compared with uninoculated intercropped wheat. The thousand-seed weight was improved by $86 \%$ in wheat intercropped and inoculated with the rhizobacteria-mycorrhizae consortium. Furthermore, higher $\mathrm{P}$ and $\mathrm{N}$ concentrations were observed in shoots and spikes of wheat intercropped with faba bean, and this increase was also observed in response to inoculation with the rhizobacteria-mycorrhizae consortium in terms of $P$ in shoots and spikes (by 74 and $18 \%$ ) of intercropped wheat. In addition, intercropped wheat has significantly accumulated sugar in the seeds for all inoculated treatments (except inoculation with mycorrhizae). Overall, these findings revealed that intercropping and inoculation yielded better, suggesting that intercropping combined with the application of beneficial microorganisms, such as rhizobacteria and mycorrhizae, have the potential to improve overall crop yield.

Keywords: intercropping, rhizobacteria, mycorrhizae, biofertilization, nutrient acquisition 


\section{INTRODUCTION}

Wheat is one of the most important crops worldwide, occupying second crop production worldwide (734 MT) after rice (1,100 MT), [IGC (International Grains Council), 2017]. Wheat is considered as the source of food for human populations and the main source of protein (Shewry and Hey, 2015), as it is considered a privileged supply for animal feed and multiple industrial applications. Almost all the nutrition of the population of the world is provided by grain foods, nearly $95 \%$ of which is mainly produced by cereal crops (Shewry and Hey, 2015). Wheat grains contain most of the nutrients, including carbohydrates (60-80\%, especially starch), proteins $(8-17 \%)$ with a sufficient amount of essential amino acids (except lysine, tryptophan, and methionine), lipids (1.5-2\%), minerals (1.5-2\%), vitamins, and fiber (Kumar et al., 2011; Shewry and Hey, 2015). However, wheat cultivation is subject to a series of constraints that lead to yield instability. In addition to biotic stresses (pests, slugs, aphids, nematodes, and fungi), abiotic stresses, such as drought, unstable rainfall, salinity, and lack of phosphorus can negatively impact the yield and quality of crops (Pandey et al., 2017; Francini and Sebastiani, 2019). More concerns about the future of wheat production have been raised by the scientific community, especially with the current climate changes and other environmental circumstances threatening the food security of the world. Therefore, finding new sustainable alternatives to improve wheat production is a major challenge for the agriculture of today.

For winter cereals, the importance of controlling nitrogen (N) inputs is becoming very crucial, in particular under the Mediterranean climate that characterizes Morocco and other neighboring African countries (Wahbi et al., 2016). Low temperatures and high autumn-spring rainfall caused very low levels of available $\mathrm{N}$ in the soil during the most important phase of the crop cycle (Wahbi et al., 2016). This can lead to unstable growth and yield of cereal crops during agricultural seasons.

In recent years, one of the discussed strategies to overcome high pressure on the agricultural sector (caused by demographic expansion) and improve wheat production sustainability is innovation in cereal-based cropping systems, including intercropping with legumes (Shewry and Hey, 2015). This agricultural practice has been well-studied, and advantages for both intercrop's growth have been demonstrated. Intercropping (growing two or more crop species or genotypes in the same space at the same time) systems based on judiciously designed plant-plant mixtures revealed many benefits in terms of resource use and yield stability (Lopes et al., 2016). Besides, intercropping can significantly reduce invasive pests and diseases, and this practice is well-reported as a solution to maintain biomass production and decrease the risk of crop failure in unpredictable environments (Lopes et al., 2016; Maxin et al., 2017) and it participates in the diversification of agricultural production and the provision of ecosystem services. Altogether, intercropping allows guaranteeing the stability of yield that is greatly affected by seasonal and climatic conditions, especially in Mediterranean areas (Brooker et al., 2015; Hamburdǎ et al., 2016; Li et al., 2020). Another technique that has been used demonstrating a comparable effect on cereal crops mainly for $\mathrm{N}$ nutrition is inoculation with plant growth-promoting rhizobacteria (PGPR) and mycorrhizae (AMF) either individually or in combination (Bechtaoui et al., 2019b; Raklami et al., 2019; Ben-laouane et al., 2020a). These PGPR possess the ability to promote plant growth and health either directly by fixing atmospheric $\mathrm{N}$, solubilizing phosphate and potassium, producing auxin, and transferring nutrients, or indirectly by producing some metabolites suppressive of phytopathogens (antibiotics, hydrogen cyanide, siderophores, and antifungal production), inducing systemic resistance, or by spatial and temporal competition (Vacheron et al., 2013; Ahemad and Kibret, 2014). Indeed, mycorrhizae can improve plant water uptake and mineral status through the transfer of water and nutrients, and exploring inaccessible soil niches (Barea et al., 2017; Raklami et al., 2019; Ben-laouane et al., 2020b).

Several studies have reported positive effects that association legumes/cereals may have on biomass yield and resource use efficiency, mainly $\mathrm{N}$ and phosphorus (P), (Li et al., 2011; Betencourt et al., 2012; Latati et al., 2013, 2014; Bargaz et al., 2017; Kaci et al., 2018). Other reports highlighted the positive impact of polymicrobial inoculation with bacteria and/or mycorrhizae on the growth and yield of cereals (Jia et al., 2004; Raklami et al., 2019). However, only a few studies have reported the combined effect of cereal-legume intercrops and microbial inoculation with rhizobacteria and/or mycorrhizae under field conditions. As per our knowledge in this research area, exploiting diversity of both crops (here as intercrops) and beneficial microbes (here rhizobacteria and mycorrhizae) could be an effective agricultural biosystem to enhance crop performance and soil fertility. To our knowledge, this study is among the first reports to investigate the effect of wheat-faba bean intercropping combined with a bacteria-mycorrhizae application under field conditions. In this regard, this study aimed to evaluate the effect of inoculation with rhizobacteria and mycorrhizae (alone or in combination) on wheat (Triticum durum) intercropped with faba bean (Vicia faba) under field conditions.

\section{MATERIALS AND METHODS}

\section{Study Site Characteristics}

The field experiment was performed during one growing season in 2017 in Tamesloht plain located about $25 \mathrm{~km}$ at the South-East of Marrakech $\left(31^{\circ} 54^{\prime} 18^{\prime \prime} \mathrm{N} ;-8^{\circ} 02^{\prime} 08^{\prime \prime} \mathrm{W}\right.$, $511 \mathrm{~m}$ above sea level, Morocco). Soil chemical properties (0$20 \mathrm{~cm}$ layer) were as follows: texture sandy-silty; $\mathrm{pH}\left(\mathrm{H}_{2} \mathrm{O}\right)$ 8.12; conductivity $(\mu \mathrm{S} / \mathrm{cm})$ 183.3; total limestone (\%) 5.04; total carbon (\%) 0.5 ; total organic matter (\%) 0.86 ; total $\mathrm{N}$ $(\mathrm{mg} / \mathrm{g})$ 9.98, assimilable P (ppm) 57. The regional climate of the experimental site is the typical Mediterranean, with $251 \mathrm{~mm}$ rainfall (from September to May) and the mean air temperatures are $28.2^{\circ} \mathrm{C}$ in autumn, $18^{\circ} \mathrm{C}$ in winter, and $26^{\circ} \mathrm{C}$ in spring. The soil in our experiment was not cultivated, benefited, or treated before by chemical fertilizers or other organic manures.

\section{Rhizobacteria and Mycorrhizae Inoculum}

The rhizobacteria used for inoculation were isolated from the rhizosphere and nodules of Vicia faba. Strains we identified using 
TABLE 1 | Characteristics of the tested rhizobacteria (Raklami et al., 2019).

\begin{tabular}{lcccc}
\hline Activity & PGP27 & BS17 & RhOF4 & RhOF155 \\
\hline Phosphate solubilization (mg/l) & 0.44 & 1.55 & 3.59 & 3.45 \\
Potassium solubilization & +++ & + & ++ & + \\
Exopolysaccharide production & 22.65 & 10.67 & 72.35 & 176.02 \\
(mg of CR/ OD 600$)$ & - & - & - & - \\
Siderophore production & 38.07 & 10.76 & 112.43 & 290.64 \\
AlA production $(\mu \mathrm{g} / \mathrm{ml})$ & ++ & + & +++ & +++ \\
Nitrogen fixation & + & + & + & - \\
Assimilation of glucose & - & + & + & + \\
Assimilation of mannitol & + & + & - & + \\
Assimilation of maltose & & & & +
\end{tabular}

+ , Low; ++ , Medium; +++ , High (for potassium solubilization and nitrogen fixation); -, absent; +, presence (for other activities); CR, Congo red.

16SrDNA as BS17 Acinetobacter sp. BS17; Rahnella aquatilis PGP27; Ensifer meliloti RhOF4; and Ensifer meliloti RhOF155. These strains were able to solubilize phosphate and potassium, produce auxin and exopolysaccharides, and fix $\mathrm{N}_{2}$ (Bechtaoui et al., 2019b; Raklami et al., 2019). The consortium used, arbuscular-mycorrhizal fungi (AMF), was isolated from the Tafilalet palm grove located $500 \mathrm{~km}$ southeast of Marrakesh, and it contains a mixture of native species: (i) Glomus sp. (15 spores/g of soil), (ii) Sclerocystis sp. (9 spores/g soil), and (iii) Acaulospora sp. (1 spore/g of soil), (Meddich et al., 2015). The main plant growth-promoting activities of these rhizobacterial strains are given in Table 1.

\section{Experimental Design and Growth Conditions}

The experimental design (split-plot) had a randomized plot, with plant species as the main factor (wheat monoculture or wheat/faba bean intercropped culture); inoculation as a subfactor, and five replication plots. The plots were $0.8 \mathrm{~m} \times 1.5 \mathrm{~m}$; each main plot was spaced $0.4 \mathrm{~m}$ from the next (to avoid any possible contamination). The crops were sown in January at the rate of $5 \mathrm{~g}$ of wheat ( $47.86 \mathrm{~g}$ as a weight of thousand seeds) per plot for the monoculture crop. When intercropped, 12 bean seeds $(1,499.16 \mathrm{~g}$ as a weight of thousand seeds) per plot were transferred to the field in three rows separated by $0.3 \mathrm{~m}$ (four seeds per row), and $5 \mathrm{~g}$ of wheat was sown randomly in the same plot. Weeds were controlled by hand during the experiment. Hence, three inoculations were examined, namely, (i) the selected rhizobacteria mixture (BS17 + PGP27 + RhOF4 + RhOF155), (PR), (ii) arbuscular mycorrhizal fungi alone (M), and, finally, (iii) the consortium rhizobacteria-mycorrhizae (PRM). The plants were inoculated with $5 \mathrm{ml}$ of bacteria mixture near the roots. A second inoculation was scheduled 15 days after the first inoculation. Treatments containing mycorrhizal fungi were inoculated with $2 \mathrm{~g}$ (fresh weight) of corn-mycorrhizae roots near the root system of each plant. An uninoculated control was used under the same conditions to determine the effect of agricultural soil native flora on the growth of wheat mono- and intercropped crops.
Watering was done with a drip irrigation system. The distance between drip lines for the same board (plot) is $40 \mathrm{~cm}$, with $15 \mathrm{~cm}$ as a distance between each internal dripper. The drip hose used was equipped with suitable internal drippers (sheath) that released 2 l/h.

\section{Arbuscular Mycorrhizal Fungi Colonization}

Arbuscular mycorrhizal fungi colonization was determined by root staining according to the methodology described by Phillips and Hayman (1970). The roots were washed and cleaned with $10 \% \mathrm{KOH}$ at $90^{\circ} \mathrm{C}$. Then, they were rinsed and suspended in lactic acid for 7-10 min at room temperature. Subsequently, the roots were stained with $0.05 \%$ trypan blue at $90^{\circ} \mathrm{C}$ for $20 \mathrm{~min}$ (Phillips and Hayman, 1970). Random root fragments $(1 \mathrm{~cm}$ length) were mounted between slide and coverslip in a drop of glycerol (15 root fragments per slide). They were then observed under a microscope to quantify the frequency of mycorrhization.

The mycorrhization frequency (percentage of root segments infection) of roots was determined by the technique described by Trouvelot et al. (1986), and was calculated as follows:

$$
F(\%)=\frac{(N-N 0)}{N} \times 100
$$

with $\mathrm{N}=$ number of observed fragments, and $\mathrm{N} 0=$ number of non-mycorrhizal fragments.

\section{Plant Growth and Yield Analysis}

Wheat was considered as the main crop and faba bean as an intercrop component. Hence, the expected benefits of the cultural practices on growth, nutrition, and yield productivity were only examined on wheat plants. After growing seasons (5 months), at wheat harvest, leaf number and spike number were counted, and spike weight was measured. Then, 10 randomly chosen plants in the middle of the plot were harvested. The seeds from each plant were collected, counted, and weighed to determine the dry weight of 1,000 seeds (grain yield). These measurements recorded on a plot basis were converted to hectare for statistical analyses. The aerial parts (without spikes) of each plant were then oven-dried at $70^{\circ} \mathrm{C}$ for 3 days and weighed to determine shoot dry weight.

\section{Plant Mineral Analysis}

Plant mineral composition ( $\mathrm{P}$ and $\mathrm{N}$ contents) was determined after mineralization. For this, $0.5 \mathrm{~g}$ of plant tissues were distributed in crucibles and placed in an oven (at $550^{\circ} \mathrm{C}$ ) for $6 \mathrm{~h}$. The ashes obtained were digested with $6 \mathrm{~N} \mathrm{HCl}$, evaporated on a hot plate, and then recovered with hot distilled water. The solutions obtained were used to determine $\mathrm{P}$ content according to the method described by Olsen and Sommers (1982). Briefly, $1 \mathrm{ml}$ of the obtained solution was added to $4 \mathrm{ml}$ distilled water and $5 \mathrm{ml} \mathrm{AB}$ reagent (A: sodium molybdate $2.5 / 100 \mathrm{ml} 10 \mathrm{~N} \mathrm{H}_{2} \mathrm{SO}_{4}$; $\mathrm{B}$ : hydrazine sulfate $0.15 \mathrm{~g} / 100$ distilled water). The mixture was then incubated for $10 \mathrm{~min}$ at $50^{\circ} \mathrm{C}$. The optical density was measured at $825 \mathrm{~nm}$, and the amount of $\mathrm{P}$ was determined according to a standard curve.

The total content of $\mathrm{N}$ in the plants was determined according to the method described by Rodier (1982); which consisted of digesting $0.5 \mathrm{~g}$ of dried plant matter using a digest block, then the 
ash was distilled with a semi-automatic distiller. $\mathrm{N}$ was collected in a solution of boric acid and assayed with a solution of diluted sulfuric acid.

\section{Plant Biochemical Analyses}

Sugar and protein contents were measured to assess the effect of intercropping and inoculation on plant biochemical analyses. For so, $0.5 \mathrm{ml}$ of the dry seeds were extracted with $10 \mathrm{ml}$ of $80 \%$ ethanol and centrifuged at $4,000 \mathrm{rpm}$ for $20 \mathrm{~min}$. The extraction was done three times to have a final volume of $30 \mathrm{ml}$ for each extract. Soluble proteins were determined according to the Bradford method, Bradford (1976). Briefly, $5 \mathrm{ml}$ Bradford reagent was added to $0.1 \mathrm{ml}$ of the plant extract. After homogenization, the reaction mixture was placed for $30 \mathrm{~min}$ at $30^{\circ} \mathrm{C}$, and then the absorbance was read at $595 \mathrm{~nm}$. Total sugar content was measured following the colorimetric method described by DuBois et al. (1956). Concisely, $200 \mu \mathrm{l}$ of phenol (5\%) and $1 \mathrm{ml}$ of $\mathrm{H}_{2} \mathrm{SO}_{4}$ were added to $0.2 \mathrm{ml}$ of the plant extract. Promptly after cooling, absorbance was measured at $485 \mathrm{~nm}$.

\section{STATISTICAL ANALYSES}

The results are means $\pm \mathrm{SD}$ of 10 determinations in growth and productivity parameters: shoot dry weight (without spikes), root dry weight, number of leaves, and number and weight of wheat spikes. Four determinations were carried out in mineral and biochemical analyses. Differences among treatments were assessed by one-way ANOVA (SPSS Statistics V21.0 Inc., Chicago, IL United States); the averages are compared by the Student, Newman, Keuls (SNK) test. Different letters indicate significant differences at $p<0.05$. Growth, yield, nutrition, and biochemical parameters and their correlation with treatments were subjected to principal component analyses (PCAs) using RStudio (4.0.3). The graphical presentation was carried out using GraphPad Prism (7.0).

\section{RESULTS}

\section{Arbuscular Mycorrhizal Fungi Colonization}

The inoculation with AMF resulted in a significant $(p<$ 0.05 ) increase in the frequency of AMF colonization in wheat monocropped and intercropped with faba beans (Figure 1). For instance, the application of mycorrhizal inoculum ( $\mathrm{M}$ treatment) increased AMF colonization by 171 , and $200 \%$ in the case of wheat monocropped and intercropped cultures. Moreover, the application of rhizobacteria ( $P R$ treatment) seemed to enhance AMF colonization in the wheat plants not inoculated with the mycorrhizal inoculum. The combined application of rhizobacteria-mycorrhizae resulted in AMF colonization $>95 \%$; however, this colonization showed no significant difference in comparison with $\mathrm{M}$ treatments.

\section{Plant Growth, Nutrition, and Yield Analyses}

The results depicted in Table 2 show that there was a significant difference in wheat biomass yield. Vegetative shoot and root biomass were enhanced in the intercropped plants compared with the monoculture plants. An improvement in the shoot

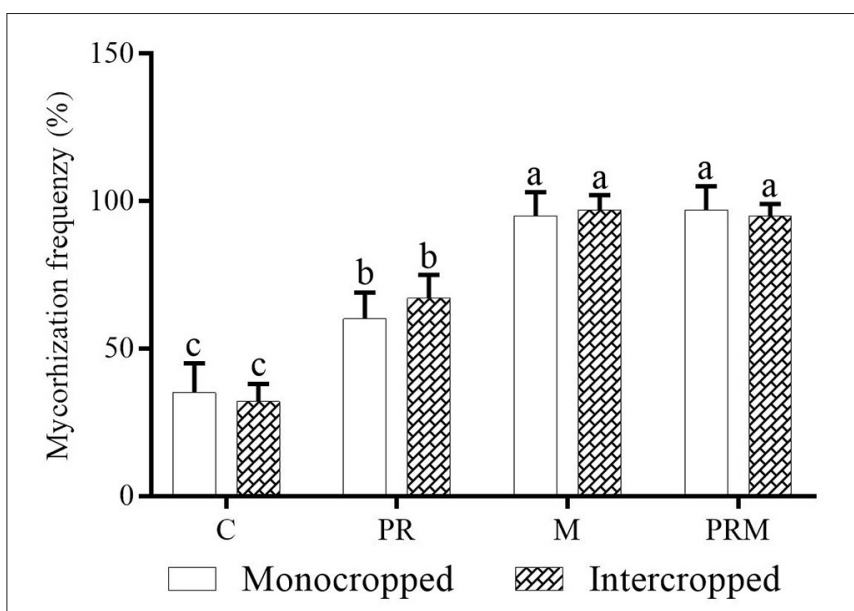

FIGURE 1 | Effect of the intercropping system and inoculation with rhizobacteria consortium (PR), mycorrhizae (M), and their combination (PRM) on arbuscular-mycorrhizal fungi (AMF) colonization, after 5 months of wheat growth under field conditions.

dry weight of $12 \%$ was observed in the case of wheat intercropped treatments $(\mathrm{C})$ compared with the same treatment in monocropped culture. In the same way, the intercropped plants exposed better leaves and yield production. For instance, the number of leaves was improved by $39 \%$, the number of spikes was enhanced by $15 \%$, and the thousand-seed weight was improved by $45 \%$. As a general pattern, the intercropped system displayed better improvement in terms of plant biomass, the number of leaves, and spike yield (spike number, weight, and thousand-seed weight). However, the uninoculated plants in both systems (mono or intercropped) generally had lower biomass and low leaf and yield production compared with the inoculated plants. The application of rhizobacteria, mycorrhizae, or their combination significantly improved the growth parameters (shoot and root dry weights and number of leaves) and yield parameters (spike number and weight) in both mono-and inter-crops compared with the uninoculated plants. Single inoculation (PR or $M$ treatments), as well as the inoculation with the mixture rhizobacteria-mycorrhizae consortium (PRM treatment), enhanced plant biomass and yield. Wheat intercrop inoculated with rhizobacteria-mycorrhizae showed the best improvement in plant biomass and yield. For instance, intercropped plants inoculated with the mixture of rhizobacteria and mycorrhizae showed an improvement of $326 \%$ in terms of shoot dry weight compared with uninoculated plants. Similarly, yield production had a similar trend. An improvement of $86 \%$ was noticed in the case of wheat plants intercropped with faba bean and inoculated with rhizobacteria and mycorrhizae compared with the uninoculated plants.

\section{Plant Mineral Analysis}

To assess the effect of the intercropping system and inoculation on wheat nutrition, shoot, and seed $\mathrm{N}$ and $\mathrm{P}$ were measured (Table 3). The results showed that $\mathrm{N}$ and $\mathrm{P}$ were improved under the intercropping system. Hence, the uninoculated plants 


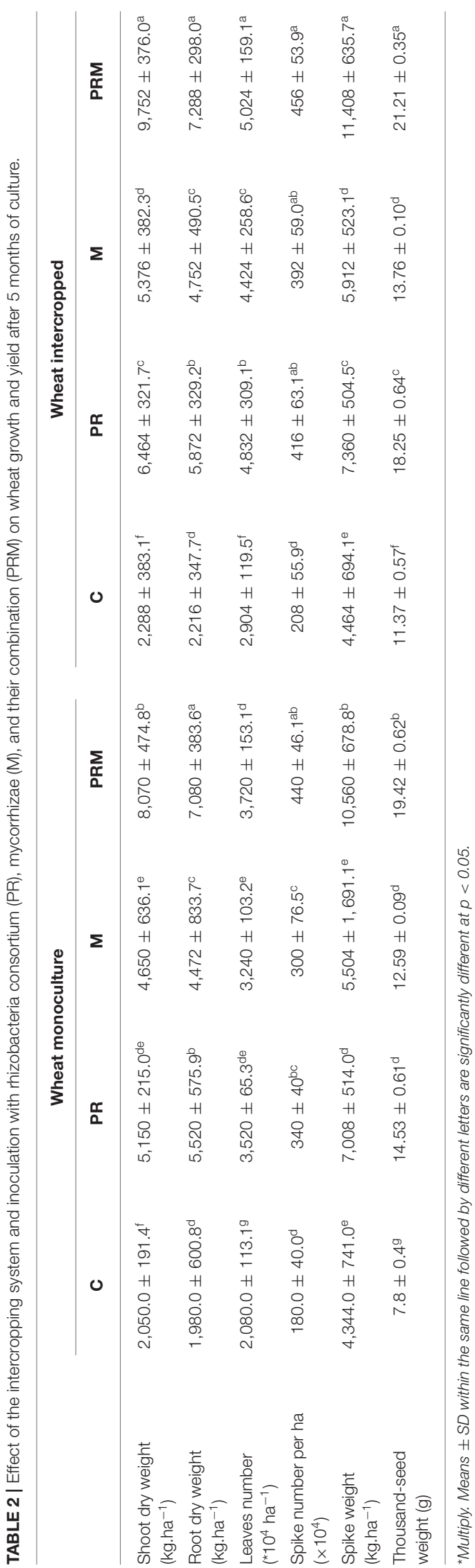

showed, respectively, an improvement of 181 and 50\% regarding shoot $\mathrm{N}$ and $\mathrm{P}$ contents. For seeds, an improvement of $41 \%$ was noticed for $\mathrm{N}$, while no significant improvement was observed for P. However, under both mono-and inter-cropped systems, the inoculated plants (with rhizobacteria, mycorrhizae, and their mixture) displayed greater improvement compared with the uninoculated plants (Table 3).

\section{Plant Biochemical Analyses}

The intercropping system proved its ability to improve sugar content in wheat seeds (Figure 2). Sugar content was significantly lower in the uninoculated and monocropped plants than the plants grown in intercropped systems. An improvement of $23 \%$ was recorded in the case of the intercropped and uninoculated plants in comparison with the monocropped plants. Furthermore, the inoculation with rhizobacteria boosted the production of sugar in both systems. Mycorrhizae application proved its effectiveness to promote sugar secretion only in the monocropped system. Moreover, the application of the rhizobacteria-mycorrhizae mixture allowed better sugar production in both systems. Regarding protein production, the intercropping system significantly enhanced protein production in wheat seeds compared with the uninoculated plants grown in the monocropped system (Figure 1). However, there was no significant difference between the mono-and intercropped plants when they were inoculated with rhizobacteria, mycorrhizae consortium, or their combination. Protein results revealed that the application of the rhizobacteria-mycorrhizae mixture (PRM) permitted better protein production in plants of both systems.

\section{Principal Component Analyses}

To study the relationship between the treatments applied and several predictor variables, a principal component analysis (PCA) was carried out. Predictor variables were reduced to 10 variables that contribute the most to result in variation. Among all the principal components, the first two components, i.e., PC1 (Dim 1) and PC2 (Dim 2), exhibited maximum contribution and accounted for $86.7 \%$ of the total variance in the dataset (Figure 3). PC1 contributed 78\%, while PC2 contributed 8.7\%, accordingly. Treatments were distributed around the two first components. Three groups were distinguished according to treatment distribution. The first group was located on the right of the first axis (PC1), which was positively correlated with growth, nutrition, yield, and biochemical parameters. The second group was located on the vertical axis and corresponded to treatment with intermediate growth, yield, nutrition, and biochemical parameters. The third group, located on the left of PC1, matched the treatment with low values. According to the PCA, wheat plants intercropped with faba beans and inoculated with the PRM showed the best improvement followed by wheat monocropped and inoculated with the PRM. The lowest improvement matched the uninoculated-mono and intercropped without inoculation.

\section{DISCUSSION}

The economic importance and role of wheat in food security and livestock cannot be disputed. Wheat is considered the most 
TABLE 3 | Effect of intercropping and inoculation with rhizobacteria consortium (PR), mycorrhizae (M), and their combination (PRM) on wheat phosphorus and nitrogen concentration after 5 months of culture.

\begin{tabular}{|c|c|c|c|c|c|c|c|c|}
\hline & \multicolumn{4}{|c|}{ Wheat monoculture } & \multicolumn{4}{|c|}{ Wheat intercropped } \\
\hline & C & PR & $\mathbf{M}$ & PRM & C & PR & $\mathbf{M}$ & PRM \\
\hline $\begin{array}{l}\text { Shoot } \mathrm{N} \text { content } \\
\left(\mathrm{mg} \cdot \mathrm{g}^{-1} \cdot \mathrm{m}^{2} \mathrm{DW}\right)\end{array}$ & $0.11 \pm 0.00^{h}$ & $0.21 \pm 0.00^{9}$ & $0.47 \pm 0.00^{c}$ & $0.58 \pm 0.00^{a}$ & $0.31 \pm 0.00^{e}$ & $0.32 \pm 0.00^{d}$ & $0.30 \pm 0.00^{f}$ & $0.54 \pm 0.00^{b}$ \\
\hline $\begin{array}{l}\text { Seed } \mathrm{N} \text { content } \\
\left(\mathrm{mg} \cdot \mathrm{g}^{-1} \cdot \mathrm{m}^{2} \mathrm{DW}\right)\end{array}$ & $0.41 \pm 0.00^{f}$ & $0.27 \pm 0.00^{h}$ & $0.60 \pm 0.00^{c}$ & $0.90 \pm 0.00^{b}$ & $0.58 \pm 1.00^{d}$ & $0.49 \pm 0.00^{e}$ & $0.29 \pm 0.00^{9}$ & $1.06 \pm 0.00^{a}$ \\
\hline $\begin{array}{l}\text { Shoot P content } \\
\left(\mathrm{mg} \cdot \mathrm{g}^{-1} \cdot \mathrm{m}^{2} \mathrm{DW}\right)\end{array}$ & $0.04 \pm 0.00^{h}$ & $0.05 \pm 0.00^{9}$ & $0.15 \pm 0.00^{a}$ & $0.12 \pm 0.00^{b}$ & $0.06 \pm 0.00^{f}$ & $0.09 \pm 0.00^{e}$ & $0.11 \pm 0.00^{d}$ & $0.12 \pm 0.00^{c}$ \\
\hline $\begin{array}{l}\text { Seed } \mathrm{P} \text { content } \\
\left(\mathrm{mg} \cdot \mathrm{g}^{-1} \cdot \mathrm{m}^{2} \mathrm{DW}\right)\end{array}$ & $0.17 \pm 0.00^{d}$ & $0.13 \pm 0.00^{9}$ & $0.40 \pm 0.00^{a}$ & $0.18 \pm 0.00^{c}$ & $0.17 \pm 0.00^{d}$ & $0.13 \pm 0.00^{f}$ & $0.14 \pm 0.00^{e}$ & $0.20 \pm 0.00^{b}$ \\
\hline
\end{tabular}

Means $\pm S D$ within the same line followed by different letters is significantly different at $p<0.05$. DW: dry weight.

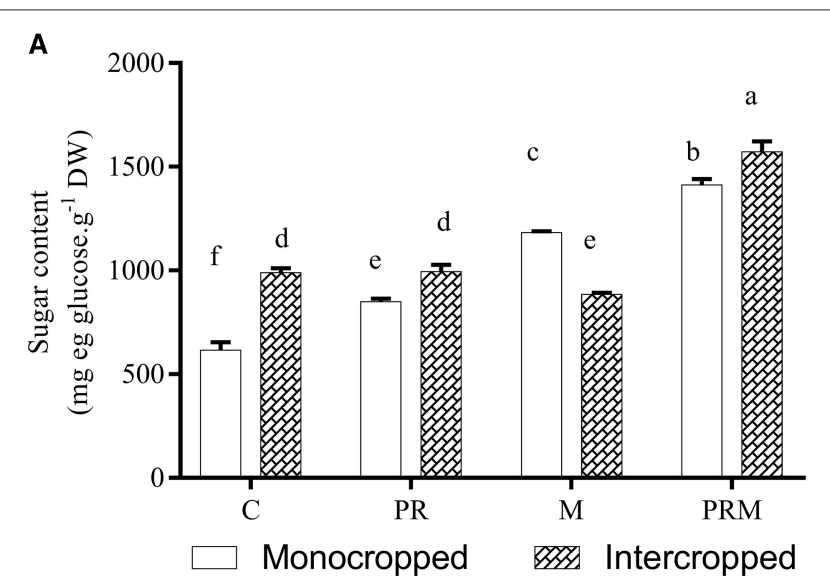

B

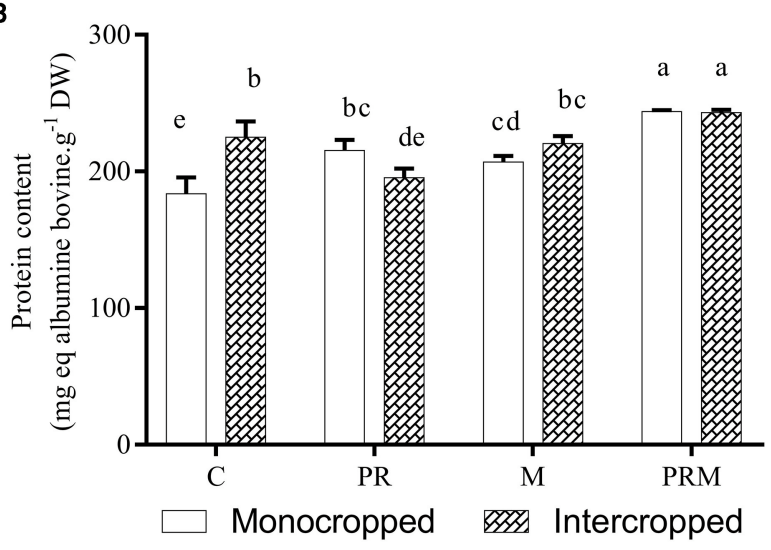

FIGURE 2 | Effect of the intercropping system and inoculation with rhizobacteria consortium (PR), mycorrhizae (M), and their combination (PRM) on (A) wheat sugar and (B) protein content after 5 months of growth under field conditions.

important crop in temperate zones. However, wheat yield is subject to a series of biotic and abiotic constraints that lead to yield instability (Abhinandan et al., 2018). Intercropping, the cultivation of at least two crops simultaneously on the same field, provides opportunities for sustainable intensification of crop production resulting in greater yield per land unit over the sole cropping system (Li et al., 2020). Indeed, the application of beneficial microorganisms could offer additional positive impacts that could sustainably harness wheat production under unfavorable circumstances (Bechtaoui et al., 2019a,b; Raklami et al., 2019). However, studies on the effect of both intercropping and microbial inoculation are scant, and there has been attracting evidence of such agricultural applied research. Accordingly, the present field study contributes knowledge on the positive effects of combining inoculation and intercropping and to what extent this strategy would improve the yield of intercropped plants, particularly wheat described in this research work.

Intercrops need to be compatible with another plant to grow on the same piece of land, as some combinations affect the yield rather than increase it (Lakshminarayanan et al., 2005). Despite that, their high demand for nutrients and water must not overlap to minimize interspecific competition. Several reports used different legume species to grow with the cereal, such as faba bean (Bechtaoui et al., 2019a; Zhang et al., 2019), cowpea (Takim, 2012), soybean (Baghdadi et al., 2016; Arshad et al., 2020), and mungbean (Arshad et al., 2020). The ability to intercrop to reduce erosion and improve soil fertility makes intercropping a wellrecommended cropping system. Legumes are less competitive, have less shading effect on grain cereals, and contribute to stimulating biological $\mathrm{N}$ fixation with positive consequences on $\mathrm{N}$ status in the rhizosphere through root exudates rich in $\mathrm{C}$ and $\mathrm{N}$ compounds (Hauggaard-Nielsen and Jensen, 2005). In this study, we have confirmed that faba bean is a suitable intercrop for wheat. This intercropping yielded better in terms of plant growth, nutrient acquisition, and grain yield. Improvement of wheat under intercropping could be explained by additional $\mathrm{N}$ provided by the faba bean intercrop through symbiotic $\mathrm{N}$ fixation. In this context, a study by Kaci et al. (2018) noted that wheat intercropped with faba bean increased shoot dry weight compared with monocultured wheat. Indeed, Cong et al. (2015) reported that either intercropping or rotation of wheat and faba bean improved $\mathrm{N}$ nutrition and crop yield. However, Fan et al. (2006) showed a decrease in growth, grain yield, and $\mathrm{N}$ acquisition when bread wheat was cultivated with faba bean. Fan et al. (2006) reported that improved wheat growth is not 


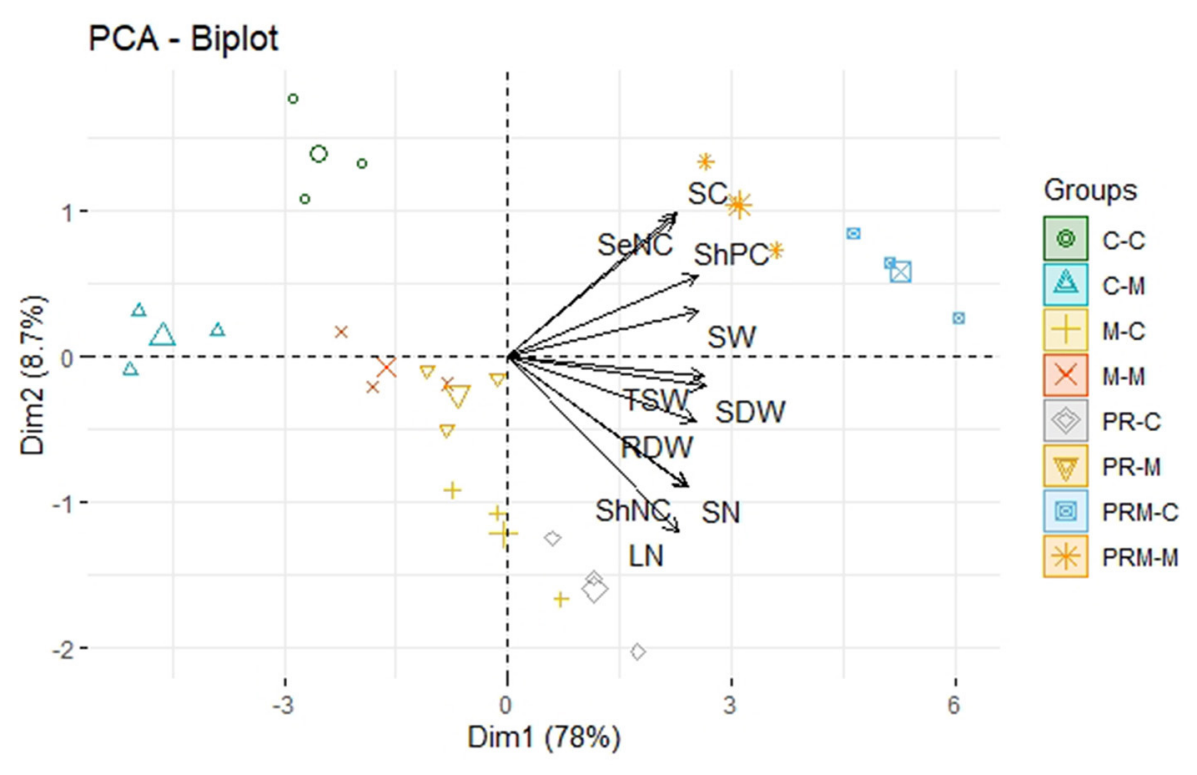

FIGURE 3 | Principal component analysis (PCA) of wheat intercropped with faba beans under $\times$ treatments (PR, inoculation with rhizobacteria consortium; M, mycorrhizae; PRM, their combination) after 5 months of growth under field conditions. SDW, shoot dry weight; RDW, root dry weight; LN, leaf number; SN, spike number; ShNC, shoot nitrogen content; TSW, thousand seed weight; SW, seed weight; ShPC, shoot phosphorus content; SC, sugar content; SeNC, seed nitrogen content.

only due to the direct effect of intercropping, but also to the role of plant inoculation using rhizobacteria exhibiting plant growthpromoting (PGP) activities, such as $\mathrm{P}$ solubilization, $\mathrm{N}$ fixation, and phytohormone production. Different consortia were used in our study for either the intercrop plants or the monocrops, containing rhizobacterial strains, in addition to mycorrhizae. Nyoki and Ndakidemi (2018) reported that intercropping of maize with rhizobacteria-inoculated soybean (Glycine max L. Merr.) enhanced maize yield compared with plants intercropped with no inoculation. Moreover, mycorrhizae application has been reported to induce other beneficial microbial communities in the rhizosphere, such as $\mathrm{N}$ symbiotic fixer species (Püschel et al., 2017). Mycorrhizae influence the roots to establish symbiosis (rhizobia-legumes) and improve the uptake of nutrients, such as N and P (Barea et al., 2005; Saia et al., 2014a,b). Indeed, the $\mathrm{N}$ and $\mathrm{P}$ concentrations in shoots and seeds of wheat plants were improved because of inoculation, especially by the PRM treatment. The AMF, in addition to rhizobia and PGPR, has facilitated the use of $\mathrm{P}$ and $\mathrm{N}$ by wheat plants (Bechtaoui et al., 2019a; Raklami et al., 2019). Phosphorus contributes as a structural element to shoot elongation and growth of young leaves, whereas inoculation enhances nodulation and $\mathrm{N}$ nutrition (Malhotra et al., 2018). Comparable patterns of results were obtained by Ingraffia et al. (2019) who demonstrated that mycorrhizal inoculation increased root biomass, root length, root density, and uptake of N, P, Fe, and Zn by wheat (in pure or mixed stands). The combination of intercropping and inoculation has also improved sugar and protein contents in seeds. The $\mathrm{N}$ fixed through the nodules contributes to the synthesis of amino acids, which are the basic unit of proteins. Abbas et al.
(2001) and Mpairwe et al. (2002) found that intercropping of forage legumes and cereals improved the protein content of plants. The interspecific facilitation between intercropped plants induced by the hyphal network and nodules contributes to the transfer of nutrients and carbohydrates to wheat plants under field conditions and further improves sugar and protein contents under intercropping and inoculation (Shaukat et al., 2006; Clautilde et al., 2011).

The density of plants is another important factor that plays a key role in improving wheat growth as well. The cultivation of all seeds at the same time led to an extreme concurrence between plants. This could reduce the growth of leaves and make them respire rather than photosynthesize and thereby affects crop yield (Rezaei-Chianeh et al., 2011). These authors have tested different densities of maize and faba bean under field conditions and found that the combination of eight maize and 50 beans $/ \mathrm{m}^{2}$ had the highest productivity and could be introduced as the best density to intercropped maize with faba beans. In the present study, plant density conditions have generally been taken into consideration. The plant density used ( 12 beans $/ 5 \mathrm{~g}$ of wheat) showed a greater improvement in terms of leaf number, plant biomass, and spikes yield (spike number, weight, and weight of thousand-seed). Therefore, it might be the ideal density in the field for growing wheat and faba beans as intercropped plants.

\section{CONCLUSION}

We investigated the effect of combined inoculation on the growth and yield of field-grown wheat intercropped with faba 
bean. Our findings clearly demonstrated that intercropping and inoculation, particularly under rhizobacteria-mycorrhizae (PRM) co-inoculation, might be considered among the best agricultural practices to boost the yield of wheat under field conditions in low-input farming systems. The intercropping combined with inoculation with beneficial microorganisms (PGPR, rhizobacteria, and/or mycorrhizae) is considered a feasible, economically affordable, and effective strategy to improve the growth and yield of wheat. However, reproducing similar experiments in other field environments with other plant species and varieties is generally required to confirm the outcomes. Additional controlled and field experiments are needed to validate both crop and microbial treatments at both the mechanistic and agronomic levels. This should also consider the need to analyze the response of the legume intercrop given the important role played in nutrient facilitation and the overall agro-ecological services provided.

\section{REFERENCES}

Abbas, M., Monib, M., Rammah, A., Fayez, M., and Hegazi, N. (2001). Intercropping of Sesbania (Sesbania sesban) and leucaena (Leucaena leucocephala) with five annual grasses under semi-arid conditions as affected by inoculation with specific rhizobia and associative diazotrophs. Agronomie 21, 517-525. doi: 10.1051/agro:2001141

Abhinandan, K., Skori, L., Stanic, M., Hickerson, N. M. N., Jamshed, M., and Samuel, M. A. (2018). Abiotic stress signaling in wheat-an inclusive overview of hormonal interactions during abiotic stress responses in wheat. Front. Plant Sci. 9, 1-25. doi: 10.3389/fpls.2018.00734

Ahemad, M., and Kibret, M. (2014). Mechanisms and applications of plant growth promoting rhizobacteria: current perspective. J. King Saud Univ. Sci. 26, 1-20. doi: 10.1016/j.jksus.2013.05.001

Arshad, M., Nawaz, R., Ahmad, S., Shah, G. A., Faiz, F., Ahmad, N., et al. (2020). Growth, yield and nutritional performance of sweet sorghum and legumes in sole and intercropping influenced by type of legume, nitrogen level and air quality. Pol. J. Environ. Stud. 29, 533-543. doi: 10.15244/pjoes/104461

Baghdadi, A., Halim, R. A., Ghasemzadeh, A., Ebrahimi, M., Othman, R., and Yusof, M. M. (2016). Effect of intercropping of corn and soybean on dry matter yield and nutritive value of forage corn. Legum. Res. 39, 976-981. doi: 10.18805/lr.v39i6.6643

Barea, J.-M., Azcón, R., and Azcón-Aguilar, C. (2017). "Mycorrhizosphere interactions to improve a sustainable production of legumes," in Microbes for Legume Improvement, eds A. Zaidi, M. Khan, J. Musarrat (Cham: Springer International Publishing), 199-225. doi: 10.1007/978-3-319-59174-2_9

Barea, J. M., Azcón, R., and Azcón-Aguilar, C. (2005). "Interactions between mycorrhizal fungi and bacteria to improve plant nutrient cycling and soil structure," in Microorganisms in soils: Roles in Genesis and Functions, eds A. Varma, and F. Buscot (Berlin: Springer-Verlag), 195-212. doi: 10.1007/3-540-26609-7_10

Bargaz, A., Noyce, G. L., Fulthorpe, R., Carlsson, G., Furze, J. R., Jensen, E. S., et al. (2017). Species interactions enhance root allocation, microbial diversity and $P$ acquisition in intercropped wheat and soybean under P deficiency. Appl. Soil Ecol. 120, 179-188. doi: 10.1016/j.apsoil.2017.08.011

Bechtaoui, N., El Alaoui, A., Raklami, A., Benidire, L., Tahiri, A. I., and Oufdou, K. (2019a). Impact of intercropping and co-inoculation with strains of plant growth-promoting rhizobacteria on phosphorus and nitrogen concentrations and yield of durum wheat (Triticum durum) and faba bean (Vicia faba). Crop Pasture Sci. 70, 649-658. doi: 10.1071/CP19067

Bechtaoui, N., Raklami, A., Tahiri, A. I., Benidire, L., El Alaoui, A., Meddich, A., et al. (2019b). Characterization of plant growth promoting rhizobacteria and their benefits on growth and phosphate nutrition of faba bean and wheat. Biol. Open 8, 1-8. doi: 10.1242/bio.043968

\section{DATA AVAILABILITY STATEMENT}

The original contributions presented in the study are included in the article/supplementary material, further inquiries can be directed to the corresponding author/s.

\section{AUTHOR CONTRIBUTIONS}

All authors listed have made a substantial, direct and intellectual contribution to the work, and approved it for publication.

\section{FUNDING}

This study was partially funded by the Project of CNRST (PPR2/2016/42), Morocco, and the Socially Responsible Projects of Cadi Ayyad University (UCAM/RSU 2018), Marrakech, Morocco.

Ben-laouane, R., Baslam, M., Ait-el-mokhtar, M., Anli, M., Boutasknit, A., Aitrahou, Y., et al. (2020a). Potential of native arbuscular mycorrhizal fungi, rhizobia, and/or green compost as alfalfa (Medicago sativa) enhancers and their mechanisms under salinity. Plant microbe interactions. Microorganisms 8:1695. doi: 10.3390/microorganisms 8111695

Ben-laouane, R., Ait-El-mokhtar, M., Anli, M., Boutasknit, A., Ait rahou, Y., Raklami, A., et al. (2020b). Green compost combined with mycorrhizae and rhizobia: a strategy for improving alfalfa growth and yield under field conditions. Gesunde Pflanzen 73, 193-207 doi: 10.1007/s10343-020-00537-z

Betencourt, E., Duputel, M., Colomb, B., Desclaux, D., and Hinsinger, P. (2012). Intercropping promotes the ability of durum wheat and chickpea to increase rhizosphere phosphorus availability in a low P soil. Soil Biol. Biochem. 46, 181-190. doi: 10.1016/j.soilbio.2011.11.015

Bradford, M. M. (1976). A rapid and sensitive method for the quantitation microgram quantities of protein utilizing the principle of protein-dye binding. Anal. Biochem. 72, 248-254. doi: 10.1016/0003-2697(76)90527-3

Brooker, R. W., Bennett, A. E., Cong, W. F., Daniell, T. J., George, T. S., Hallett, P. D., et al. (2015). Improving intercropping: a synthesis of research in agronomy, plant physiology and ecology. New Phytol. 206, 107-117. doi: $10.1111 / \mathrm{nph} .13132$

Clautilde, M., Enama, A., and Robert, N. (2011). Effect simultané de la dilution et de la combinaison du Rhizobium et des mycorhizes sur la production foliaire et les propriétés physico-chimiques des jeunes feuilles de Vigna unguiculata (L.) Walp. J. Appl. Biosci. 40, 2668-2676. Available online at: http://m.elewa.org/ JABS/2011/40/3.pdf

Cong, W. F., Hoffland, E., Li, L., Six, J., Sun, J. H., Bao, X. G., et al. (2015). Intercropping enhances soil carbon and nitrogen. Glob. Chang. Biol. 21, 1715-1726. doi: $10.1111 / \mathrm{gcb} .12738$

DuBois, M., Gilles, K. A., Hamilton, J. K., Rebers, P. A., and Smith, F. (1956). Colorimetric method for determination of sugars and related substances. Anal. Chem. 28, 350-356. doi: 10.1021/ac60111a017

Fan, F., Zhang, F., Song, Y., Sun, J., Bao, X., Guo, T., et al. (2006). Nitrogen fixation of faba bean (Vicia faba L.) interacting with a nonlegume in two contrasting intercropping systems. Plant Soil 283, 275-286. doi: 10.1007/s11104-006-0019-y

Francini, A., and Sebastiani, L. (2019). Abiotic stress effects on performance of horticultural crops. Horticulturae 5:67. doi: 10.3390/horticulturae5040067

Hamburdǎ, S. B., Teliban, G. C., Munteanu, N., and Stoleru, V. (2016). Effect of intercropping system on the quality and quantity of runner bean (Phaseolus coccineus L.). Not. Bot. Horti. Agrobot. Cluj. Napoca 44, 613-618. doi: $10.15835 /$ nbha 44210260

Hauggaard-Nielsen, H., and Jensen, E. S. (2005). "Facilitative root interactions in intercrops," in Root Physiology: From Gene to Function (Dordrecht: Springer), 237-250. doi: 10.1007/1-4020-4099-7_13 
IGC (International Grains Council) (2017). Grain Market Report 483. Available online at: https://www.igc.int/en/default.aspx (accessed November 23, 2017).

Ingraffia, R., Amato, G., Frenda, A. S., and Giambalvo, D. (2019). Impacts of arbuscular mycorrhizal fungi on nutrient uptake, $\mathrm{N}_{2}$ fixation, $\mathrm{N}$ transfer, and growth in a wheat/faba bean intercropping system. PLOS ONE 14, 1-16. doi: 10.1371/journal.pone.0213672

Jia, Y., Gray, V. M., and Straker, C. J. (2004). The influence of rhizobium and arbuscular mycorrhizal fungi on nitrogen and phosphorus accumulation by Vicia faba. Ann. Bot. 94, 251-258. doi: 10.1093/aob/mch135

Kaci, G., Blavet, D., Benlahrech, S., Kouakoua, E., Couderc, P., Deleporte, P., et al. (2018). The effect of intercropping on the efficiency of faba bean-rhizobial symbiosis and durum wheat soil-nitrogen acquisition in a Mediterranean agroecosystem. Plant Soil Environ. 64, 138-146. doi: 10.17221/9/2018-PSE

Kumar, P., Yadava, R. K., Gollen, B., Kumar, S., Verma, R. K., and Yadav, S. (2011). Nutritional contents and medicinal properties of wheat: a review. Life Sci. Res. 22:1-10. Available online at: https://www.researchgate.net/profile/PawanYadav-20/publication/280920597

Lakshminarayanan, M., Haripriya, K., Manivannan, K., and Kamalakannan, S. (2005). Evaluation of leguminous vegetables as intercrops in pruned fields of jasmine (Jasminum samsambac Ait.). J. Spices Aromatic Crops 1, 61-64. Available online at: https://www.cabdirect.org/cabdirect/abstract/20053132243

Latati, M., Blavet, D., Alkama, N., Laoufi, H., Drevon, J. J., Gérard, F., et al. (2014). The intercropping cowpea-maize improves soil phosphorus availability and maize yields in an alkaline soil. Plant Soil 385, 181-191. doi: 10.1007/s11104-014-2214-6

Latati, M., Pansu, M., Drevon, J.-J., and Ounane, S. M. (2013). Advantage of intercropping maize (Zea mays L.) and common bean (Phaseolus vulgaris L.) on yield and nitrogen uptake in Northeast Algeria. Int. J. Res. Appl. Sci. 1, 1-7. Available online at: https://www.researchgate.net/publication/304084470

Li, C., Hoffland, E., Kuyper, T. W., Yu, Y., Zhang, C., Li, H., et al. (2020). Syndromes of production in intercropping impact yield gains. Nat. Plants 6, 653-660. doi: 10.1038/s41477-020-0680-9

Li, H., Huang, G., Meng, Q., Ma, L., Yuan, L., Wang, F., et al. (2011). Integrated soil and plant phosphorus management for crop and environment in China. A review. Plant Soil 349, 157-167. doi: 10.1007/s11104-011-0909-5

Lopes, T., Hatt, S., Xu, Q., Chen, J., Liu, Y., and Francis, F. (2016). Wheat (Triticum aestivum L.)-based intercropping systems for biological pest control. Pest Manag. Sci. 72, 2193-2202. doi: 10.1002/ps.4332

Malhotra, H., Vandana, A., Sharma, S., and Pandey, R. (2018). "Phosphorus nutrition: plant growth in response to deficiency and excess," in Plant Nutrients and Abiotic Stress Tolerance, eds M. Hasanuzzaman, M. Fujita, H. Oku, K. Nahar, and B. Hawrylak-Nowak (Gateway East: Springer) 171-190. doi: 10.1007/978-981-10-9044-8_7

Maxin, G., Andueza, D., Le Morvan, A., and Baumont, R. (2017). Effect of intercropping vetch (Vicia sativa L.), field pea (Pisum sativum L.) and triticale (X Triticosecale) on dry-matter yield, nutritive and ensiling characteristics when harvested at two growth stages. Grass Forage Sci. 72, 777-784. doi: 10.1111/gfs.12277

Meddich, A., Jaiti, F., Bourzik, W., Asli, A., El and Hafidi, M. (2015). Use of mycorrhizal fungi as a strategy for improving the drought tolerance in date palm (Phoenix dactyliferaL). Sci. Hortic. 192, 468-474. doi: 10.1016/j.scienta.2015.06.024

Mpairwe, D. R., Sabiiti, E. N., Ummuna, N. N., Tegegne, A., and Osuji, P. (2002). Effect of intercropping cereal crops with forage legumes and source of nutrients on cereal grain yield and fodder dry matter yields. Afr. Crop Sci. J. 10, 81-97 doi: 10.4314/acsj.v10i1.27559

Nyoki, D., and Ndakidemi, P. A. (2018). Yield response of intercropped soybean and maize under rhizobia (Bradyrhizobium japonicum) inoculation and P and K fertilization. Commun. Soil Sci. Plant Anal. 49, 1168-1185. doi: $10.1080 / 00103624.2018 .1455846$

Olsen, S., and Sommers, L. (1982). "Phosphorus," in Methods of Soil Analysis. Part 2. Chemical and Microbiological Properties of Phosphorus, eds A. L. Page, R. H. Miller, and D. R. Keeney (Madison: Soil Science Society of America), 403-430. doi: 10.2134/agronmonogr9.2.2ed.c24

Pandey, P., Irulappan, V., Bagavathiannan, M. V., and Senthil-Kumar, M. (2017). Impact of combined abiotic and biotic stresses on plant growth and avenues for crop improvement by exploiting physiomorphological traits. Front. Plant Sci. 8:537. doi: 10.3389/fpls.2017. 00537
Phillips, J. M., and Hayman, D. S. (1970). Improved procedures for clearing roots and staining parasitic and vesicular-arbuscular mycorrhizal fungi for rapid assessment of infection. Trans. Brit. Mycol. Soc. 55, 158-161. doi: 10.1016/S0007-1536(70)80110-3

Püschel, D., Janoušková, M., Vorišková, A., Gryndlerová, H., Vosátka, M., and Jansa, J. (2017). Arbuscular mycorrhiza stimulates biological nitrogen fixation in two Medicago spp. through improved phosphorus acquisition. Front. Plant Sci. 8:390. doi: 10.3389/fpls.2017.00390

Raklami, A., Bechtaoui, N., Tahiri, A. I., Anli, M., Meddich, A., and Oufdou, K. (2019). Use of rhizobacteria and mycorrhizae consortium in the open field as a strategy for improving crop nutrition, productivity and soil fertility. Front. Microbiol. 10:1106. doi: 10.3389/fmicb.2019.01106

Rezaei-Chianeh, E., Nassab, A. D. M., Shakiba, M. R., GhassemiGolezani, K., Aharizad, S., and Shekari, F. (2011). Intercropping of maize (Zea mays L.) and faba bean (Vicia faba L.) at different plant population densities. Afr. J. Agric. Res. 6, 1786-1793. doi: 10.5897/AJAR1 0.288

Rodier, J. (1982). L'analyse de l'eau : eaux naturelles, eaux résiduaires, eaux de mer (7éme édition). Paris: Dunod.

Saia, S., Amato, G., Frenda, A. S., Giambalvo, D., and Ruisi, P. (2014a). Influence of arbuscular mycorrhizae on biomass production and nitrogen fixation of berseem clover plants subjected to water stress. PLoS ONE 9:e90738. doi: 10.1371/journal.pone.0090738

Saia, S., Benítez, E., García-Garrido, J. M., Settanni, L., Amato, G., and Giambalvo, D. (2014b). The effect of arbuscular mycorrhizal fungi on total plant nitrogen uptake and nitrogen recovery from soil organic material. J. Agri. Sci. 152, 370-378. doi: 10.1017/S002185961300004X

Shaukat, K., Affrasayab, S., and Shahida, H. (2006). Growth responses of Triticum aestivum to plant growth promoting rhizobacteria used as a biofertilizer. Res. J. Microbiol. 1, 330-338. doi: 10.3923/jm.2006.330.338

Shewry, P. R., and Hey, S. J. (2015). The contribution of wheat to human diet and health. Food Energy Secur. 4, 178-202. doi: 10.1002/fes3.64

Takim, F. O. (2012). Advantages of maize-cowpea intercropping over sole cropping through competition indices. J. Agric. Biodivers. Res. 1, 53-59. Available online at: https://www.researchgate.net/profile/Felix-Takim/publication/263541207

Trouvelot, A., Kough, J. L., and Gianinazzi-Pearson, V. (1986). "Measurement of VA mycorrhizal rate of a root system estimation methods research with functional significance," in Physiological and Genetical Aspects of Mycorrhizae, eds V. Gianinazzi-Pearson and S. Gianinazzi (Paris: INRA), 217-221.

Vacheron, J., Desbrosses, G., Bouffaud, M.-L., Touraine, B., Moënne-Loccoz, Y., Muller, D., et al. (2013). Plant growth-promoting rhizobacteria and root system functioning. Front. Plant Sci. 4:356. doi: 10.3389/fpls.2013.00356

Wahbi, S., Maghraoui, T., Ha, M., Sanguin, H., Oufdou, K., Prin, Y., et al. (2016). Enhanced transfer of biologically fixed $\mathrm{N}$ from faba bean to intercropped wheat through mycorrhizal symbiosis. Front. Plant Sci. 107, 91-98. doi: 10.1016/j.apsoil.2016.05.008

Zhang, C., Dong, Y., Tang, L., Zheng, Y., Makowski, D., Yu, Y., et al. (2019). Intercropping cereals with faba bean reduces plant disease incidence regardless of fertilizer input; a meta-analysis. Eur. J. Plant Pathol. 154, 931-942. doi: 10.1007/s10658-019-01711-4

Conflict of Interest: The authors declare that the research was conducted in the absence of any commercial or financial relationships that could be construed as a potential conflict of interest.

Publisher's Note: All claims expressed in this article are solely those of the authors and do not necessarily represent those of their affiliated organizations, or those of the publisher, the editors and the reviewers. Any product that may be evaluated in this article, or claim that may be made by its manufacturer, is not guaranteed or endorsed by the publisher.

Copyright (c) 2021 Raklami, Bechtaoui, Tahiri, Slimani, Bargaz, Meddich and Oufdou. This is an open-access article distributed under the terms of the Creative Commons Attribution License (CC BY). The use, distribution or reproduction in other forums is permitted, provided the original author(s) and the copyright owner(s) are credited and that the original publication in this journal is cited, in accordance with accepted academic practice. No use, distribution or reproduction is permitted which does not comply with these terms. 